\title{
Acute esophageal necrosis and low-flow state
}

\author{
Ahmad Burtally MD ${ }^{1}$, Philippe Gregoire MD FRCPC ${ }^{2}$
}

\begin{abstract}
A Burtally, P Gregoire. Acute esophageal necrosis and low-flow state. Can J Gastroenterol 2007;21(4):245-247.

Acute esophageal necrosis (AEN), also called black esophagus, is quite exceptional. Endoscopic findings show circumferential black discolouration of the esophagus with or without exudates. The etiology of AEN is presently unknown and is assumed to be multifactorial. Distal esophageal involvement with proximal extension ending sharply at the gastroesophageal junction is the most common presentation. The present case report describes the clinical and endoscopic evolution of black esophagus observed in a patient with significant peripheral vascular disease, who was presented to the intensive care unit at the Hopital Saint-Francois d'Assise (Quebec City, Quebec). Through an extensive review of the literature, common underlying clinical conditions of patients diagnosed with AEN have been identified.
\end{abstract}

\section{Nécrose œsophagienne aiguë et bas débit}

La nécrose œsophagienne aiguë (NOA), aussi appelée « œsophage noir », est un événement rare. Les examens endoscopiques révèlent une coloration noire, circonférentielle de l'œsophage, avec ou sans exsudat. On ne connaît pas l'étiologie de la NOA et on croit qu'elle est plurifactorielle. La maladie consiste le plus souvent en une atteinte distale de l'œsophage avec une extension proximale se terminant abruptement à la jonction oeso-gastrique. Le présent rapport décrit l'évolution d'un cas d'œsophage noir chez un patient atteint d'une grave maladie vasculaire périphérique admis aux soins intensifs de l'hôpital Saint-François d'Assise (Québec, Québec). Après un examen approfondi de la littérature, il a été possible de recenser les pathologies cliniques sous-jacentes souvent rencontrées chez les patients victimes de NOA.

Key Words: Acute esophageal necrosis; Black esophagus

\begin{abstract}
A cute esophageal necrosis (AEN) is described, based on endoscopic findings, as a dark lesion distributed in a circumferential manner mainly in the distal one-third of the esophagus (1). Histologically, necrosis involves the mucosal and submucosal layers of the esophagus. Its exact prevalence is unknown, and in one prospective study (2) it was estimated to be $0.2 \%$. The first endoscopic description was reported in 1990 by Goldenberg et al (3). In the present report, we describe the clinical and endoscopic characteristics of a patient diagnosed with AEN in whom a transient low-flow state may have been the root of the insult. Through an extensive review of the literature, we identify common underlying clinical conditions of patients diagnosed with AEN and comment on the pathogenesis and prognosis of this clinical entity.
\end{abstract}

\section{CASE PRESENTATION}

A 77-year-old man with peripheral vascular disease (right renal artery stenosis who underwent left aortofemoral bypass) was admitted to the Hopital Saint-Francois d'Assise (Quebec City, Quebec) with a diagnosis of acute right limb ischemia. He underwent surgical thrombectomy and fasciotomy. Due to myoglobinuria with acute renal failure (plasma creatinine levels rose from $90 \mu \mathrm{mol} / \mathrm{L}$, observed two days before admission, to $164 \mu \mathrm{mol} / \mathrm{L})$, he was admitted to the intensive care unit for closer monitoring. Alkalinization of his urine with bicarbonate and rehydration to increase urine output (greater than $100 \mathrm{~mL} / \mathrm{h}$ ) was initiated. Renal function was restored (plasma creatinine levels dropped back to $90 \mu \mathrm{mol} / \mathrm{L}$ ), and furosemide therapy ( $80 \mathrm{mg}$ per day) was initiated on day 2 due to mild hypervolemia. The patient was also on extensive medications (bisoprolol, nifedipine, clonidine and hydralazine) for renovascular hypertension. Despite these medications, his systolic blood pressure remained around $170 \mathrm{mmHg}$ to $180 \mathrm{mmHg}$, and his diastolic pressure was around $60 \mathrm{mmHg}$ to $90 \mathrm{mmHg}$.

On day 3 after admission, the patient presented with left facial hemiparesis and left upper limb paresis for approximately $1.5 \mathrm{~h}$. A computed tomography scan of the brain on the same day did not show any hemorrhage or acute ischemic lesions. Intravenous (IV) heparin infusion was started, and cervical Doppler examination revealed right internal carotid occlusion at $100 \%$ and left internal carotid stenosis at $50 \%$ to $69 \%$.

On day 5 , the patient was found in his bed with acute confusion and left hemiparesis. His body temperature was normal. He did not present any respiratory distress, and his cardiac rhythm was sinusal with a regular pulse of approximately 95 beats/min and a blood pressure of approximately 110/65 mmHg. Pupillary reflex was normal with a score of 13 on the Glasgow coma scale. Abdominal examination was normal and a digital rectal examination showed melena. Neurological examination was abnormal for marked reduced force of the left upper and lower extremities. Laboratory tests revealed hemoglobin levels of $70 \mathrm{~g} / \mathrm{L}$, that dropped from $95 \mathrm{~g} / \mathrm{L}$ which was observed the day before. The international normalized ratio was 1.14 and the activated partial prothrombin time was $73 \mathrm{~s}$. A nasogastric tube drained approximately $1.3 \mathrm{~L}$ of dark brown liquid within $30 \mathrm{~min}$. Endoscopic evaluation at bedside revealed a black esophagus in the middle and distal one-third, with clear-cut margin at the gastroesophageal junction. The gastric mucosa was normal. At the gastroesophageal junction, right at the margin between normal and pathological mucosa, two sites of active bleeding were identified that were controlled with 1:10,000 adrenaline injection. The distal onethird of the esophagus was rigid and did not collapse upon suction (Figure 1). Biopsies were taken, and showed only necrotic

${ }^{1}$ Divison of Surgery; ${ }^{2}$ Division of Gastroenterology, Laval University, Le Centre hospitalier universitaire de Quebec, Quebec City, Quebec Correspondence: Dr Ahmad Burtally, Division of Surgery, Laval University, 3370 Pavillon Ferdinand Vandry, Sainte-Foy, Quebec G1K 7 P4.

Telephone 418-265-6725, fax 418-656-3821, e-mail aburta@moris.org

Received for publication May 8, 2006. Accepted May 15, 2006 


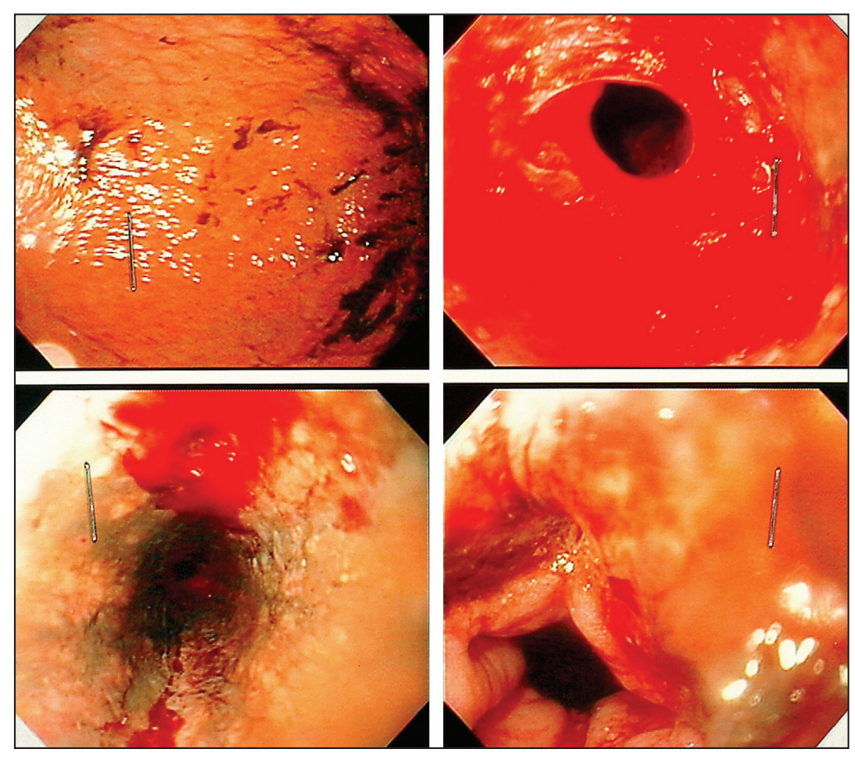

Figure 1) Normal stomach mucosa stained with blood (upper left) and distal esophagus with active bleeding (upper right). Black esophagus revealed after irrigation and active bleeding sites identified (lower left), and transitional zone intact (lower right)

material. A thoracic computed tomography scan without infusion revealed no air in the mediastinum.

IV pantoprazole perfusion was started and heparin was reversed with IV protamine. The patient received two units of packed red blood cells. Within $3 \mathrm{~h}$, his neurological symptoms subsided and he regained normal mental status. A detailed questionnaire about recent gastrointestinal (GI) symptoms was negative.

Complete bowel rest with parenteral nutrition was initiated, and no melena or hematemesis recurred. Hemoglobin fell to low levels on two occasions - the same evening it dropped to $79 \mathrm{~g} / \mathrm{L}$ and the next morning it was $80 \mathrm{~g} / \mathrm{L}$ - but transfusion of one unit of packed red blood cells was sufficient each time. No other signs of active bleeding were noted. Because of underlying carotid stenosis, hemoglobin values greater than $85 \mathrm{~g} / \mathrm{L}$ were aimed for, and nitroglycerine infusion was started to maintain a systolic blood pressure between $130 \mathrm{mmHg}$ and $160 \mathrm{mmHg}$.

On day 10, five days after the diagnosis of AEN, repeat upper endoscopic examination was obtained. The esophageal mucosa showed marked improvement with a pink appearance and no signs of bleeding. A white exudate was still present (Figure 2). IV pantoprazole was switched to oral formulation, $40 \mathrm{mg}$ administered twice a day. A liquid diet was started the next day and was well tolerated. No signs of upper GI bleeding were noted ever since.

A third upper digestive endoscopy was performed 27 days after the initial diagnosis of AEN, while the patient was still in the hospital on oral pantoprazole. He denied any digestive symptoms, had no dysphagia or odynophagia. This examination revealed a normal esophageal mucosa with superficial erosions at the distal one-third. There was no sign of stenosis.

\section{DISCUSSION}

\section{Clinical manifestation and definition}

'Black esophagus' is a very rare condition in which the clinical manifestation varies from epigastric pain to upper GI bleeding

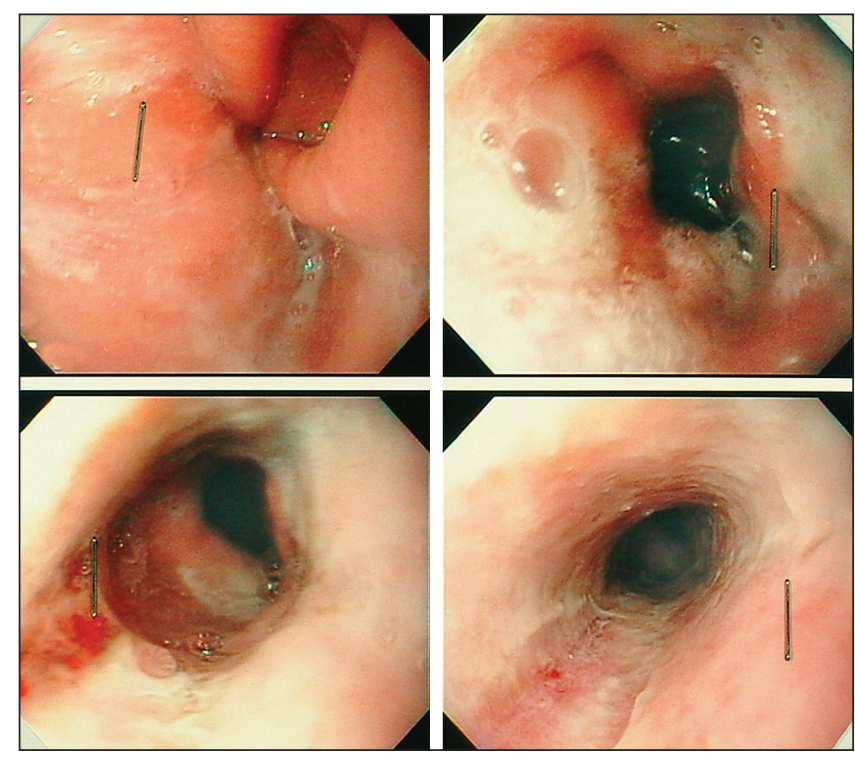

Figure 2) Gastroesophageal junction (upper left and right), transitional zone (lower left) and middle one-third of the esophagus (lower right)

with hemodynamic instability $(2,4)$, with spontaneous resolution following supportive care. Mild clinical presentations such as epigastric pain or burning, dysphagia, odynophagia and abdominal pain can be easily confounded with reflux esophagitis. Several studies $(5,6)$ claim that, as a result, AEN is often underdiagnosed and this may explain the low prevalence currently reported. Endoscopy remains the most essential tool for the diagnosis of AEN. Before the liberal use of endoscopy, the only cases reported were from autopsy studies (7). Moreto et al (4) identified three criteria for the diagnosis of AEN:

1. Acutely presenting clinical condition with an endoscopic picture consisting of a diffusely black esophagus, with or without black exudates;

2. preferential impairment of the distal one-third, without esophageal ulcers, and ending sharply at the transitional line; and

3. exclusion of caustic or other known esophageal injuring agents.

\section{Differential diagnosis}

A similar picture is also seen after ingestion of corrosive agents, which cause third-degree burns of the esophagus (in this case, proximal lesions are more important than distal involvement), whereas focal areas of esophageal mucosal necrosis are also described after ingestion of quinidine (8). Melanosis (9) of the esophagus, pseudomelanosis (10) of the esophagus and acanthosis nigricans (11) are other conditions that should be considered in the differential diagnosis.

\section{A vascular or peptic problem?}

Cases currently cited in the medical literature are similar in the clinical history: patients are often elderly with metabolic disturbances due to diabetes (1), cirrhosis (12), cancer (6) or acute conditions, such as low-flow state secondary to cardiac failure (7), hypothermia (13), prolonged hypotension (14) or sepsis (5). The precise etiology of AEN is undefined, and the 
debate over an ischemic origin versus gastroesophageal reflux diseases as the initial insult is still open.

Despite the extensive vascularization of the esophagus (15), most studies suggest an ischemic origin of AEN. The preferential location of the lesion is the distal segment of the esophagus, which has been shown to be less vascularized in anatomical studies and angiographic examinations $(16,17)$. Moreto et al (4) reported 10 patients with AEN, all of whom had associated conditions to tissue hypoperfusion (diabetes, low arterial oxygen partial pressure and dehydration). One could speculate from these data that mucosal blood flow impairment as seen in shock, hypovolemia, hypoxemia, diabetes and vascular disease could work as an initial insult through ischemia and reperfusion, thus allowing a peptic aggression to disturb mucosal integrity, as in the case of stress ulcer elsewhere in the GI tract (18).

On the other hand, gastroesophageal reflux secondary to gastric outlet obstruction syndrome from gastric volvulus, duodenal ulcer, pylorus obstruction or abdominal surgery (10) is another possible primary insult (5). Lacy et al (5) reviewed 21 cases of AEN and 13 of those were found to have duodenal ulcers, severe duodenitis or an abnormal pylorus at endoscopy or autopsy. In this case, the authors suggest that exposure of the distal segment of the esophagus to large amounts of reflux material, such as hydrogen ions, bile salts and pepsin, leads to a decline in local esophageal blood flow (19).

The prognosis of AEN is variable. Mortality is $35 \%$ to $50 \%$ and closely related to the underlying critical clinical conditions $(4,5)$. Treatment is mainly supportive and consists of maintaining hemodynamic stability through adequate volemic resuscitation and minimizing acid exposure with IV proton pump inhibitors. The use of prophylactic antibiotics is not

\section{REFERENCES}

1. Carneiro M, Lescano M, Romanello L, et al. Acute esophageal necrosis. Dig Endosc 2005;17:89-92.

2. Soussan EB, Savoye G, Hochain P et al. Acute esophageal necrosis: A 1-year prospective study. Gastrointest Endosc 2002;56:213-7.

3. Goldenberg SP, Wain SL, Marignani P. Acute necrotizing esophagitis. Gastroenterology 1990;98:493-6.

4. Moreto M, Ojembarrena E, Zaballa M, Tanago JG, Ibanez S. Idiopathic acute esophageal necrosis: Not necessarily a terminal event. Endoscopy 1993;25:534-8.

5. Lacy BE, Toor A, Bensen SP, Rothstein RI, Maheshwari Y. Acute esophageal necrosis: Report of two cases and a review of the literature. Gastrointest Endosc 1999;49:527-32.

6. Jacobsen NO, Christiansen J, Kruse A. Incidence of oesophageal necrosis in an autopsy material. APMIS 2003;111:591-4.

7. Etienne JP, Roge J, Delavierre P, Veyssier P. Nécroses de l'oesophage d'origine vasculaire. Sem Hop Paris 1969;45:1599-606.

8. Mason SJ, O’Meara TF. Drug-induced esophagitis. J Clin Gastroenterol 1981;3:115-20.

9. Archer HA, Owen WJ. Primary malignant melanoma of the esophagus. Dis Esophagus 2000;13:320-3.

10. Reichart M, Busch OR, Bruno MJ, Van Lanschot JJ. Black esophagus: A view in the dark. Dis Esophagus 2000;13:311-3.

11. Kozlowski LM, Nigra TP. Esophageal acanthosis nigricans in association with adenocarcinoma from an unknown primary site. J Am Acad Dermatol 1992;26:348-51.

12. Khan AM, Hundal R, Ramaswamy V, Korsten M, Dhuper S. Acute esophageal necrosis and liver pathology, a rare combination. World J Gastroenterol 2004;10:2457-8. recommended (5). Patients who fully recovered did not describe any upper GI symptoms during follow-up visits (2). In one case, manometric studies (10) revealed normal esophageal peristalsis and lower esophageal sphincter pressure seven months after AEN. Esophageal stenosis (4), the main late complication, is seen in approximately $15 \%$ to $20 \%$ of patients and is reported to occur within the first seven to 14 days of the onset of the disease. Fortunately, this condition seems to respond well to repeated sessions of esophageal dilation by bougienage. Two cases of esophageal perforation have been described following full-thickness necrosis of the esophagus $(4,20)$; one was fatal, while the other required surgery with colon interposition.

\section{CONCLUSION}

In the present case report, transient low-flow state due to antihypertensive medications may have initiated the ischemic insult in the possibly diseased esophageal vasculature. Prolonged acid exposure at the distal esophagus, through prolonged bedrest, may have further disrupted the mucosal integrity. High-dose IV proton pump inhibitor therapy could have helped to increase intraluminal $\mathrm{pH}$ levels, thus protecting esophageal mucosa, and favouring progressive re-epithelialization and healing. The acute fall in systolic pressures and hemoglobin levels due to lower esophageal bleeding explained the acute ischemic attack presented by the patient.

As mentioned in many studies (1,5), AEN will soon become a more familiar entity with more routine use of endoscopy in the critical care setting. While it is rarely the main cause of death in the critically ill patient, its proper identification and management could reduce morbidity, improve survival outcomes and reduce length of hospital stays.

13. Cadot P, Duverger V, Imperato M, Lapprand M, Vergos M. Esophage noir associé à une hypothermie. Ann Chir 2001;126:903-5.

14. Haviv YS, Reinus C, Zimmerman J. "Black esophagus": A rare complication of shock. Am J Gastroenterol 1996;91:2432-4.

15. Liebermann-Meffert DM, Luescher U, Neff U, Ruedi TP, Allgower M. Esophagectomy without thoracotomy: Is there a risk of intramediastinal bleeding? A study on blood supply of the esophagus. Ann Surg 1987;206:184-92.

16. Aharinejad S, Lametschwandtner A, Franz P, Firbas W. The vascularization of digestive tract studied by scanning electron microscopy with emphasis on the teeth, esophagus, stomach, small and large intestine, pancreas, and liver. Scanning Microsc 1991;5:811-49. (Erratum in 1992;6:ii).

17. Shapiro AL, Robillard GL. The esophageal arteries their configurational anatomy and variations in relation to surgery. Ann Surg 1950;131:171-85.

18. Fennerty MB. Pathophysiology of the upper gastrointestinal tract in the critically ill patient: Rationale for the therapeutic benefits of acid suppression. Crit Care Med 2002;360:S351-5.

19. Bass BL, Schweitzer EJ, Harmon JW, Kraimer J. H+ back diffusion interferes with intrinsic reactive regulation of esophageal mucosal blood flow. Surgery 1984;96:404-13.

20. Cappell SM. Esophageal necrosis and perforation associated with the anticardiolipin antibody syndrome. Am J Gastroenterol 1994;89:1241-5. 


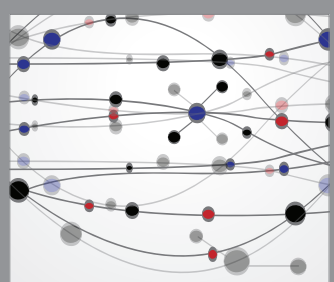

The Scientific World Journal
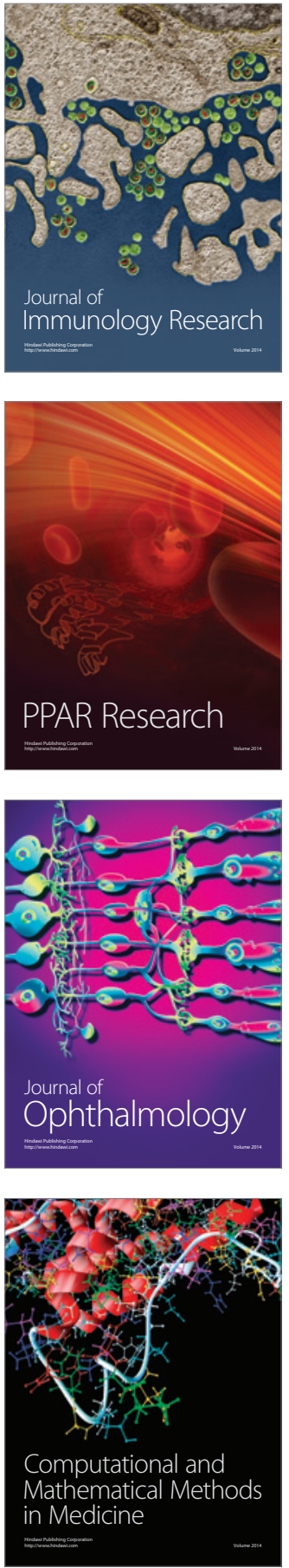

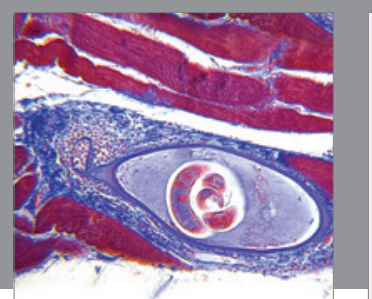

Gastroenterology Research and Practice

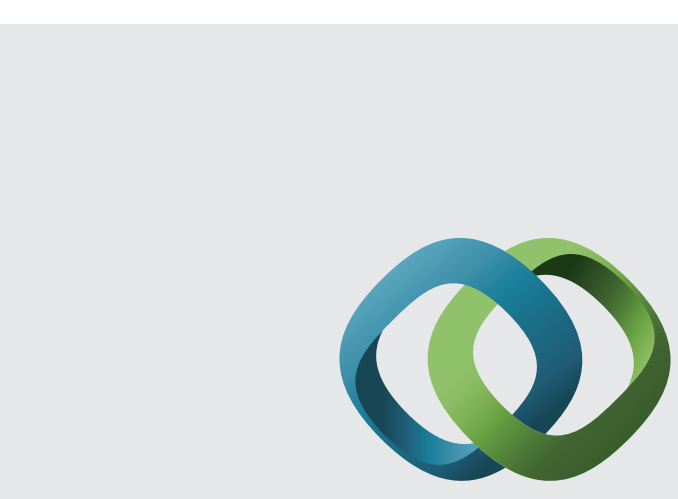

\section{Hindawi}

Submit your manuscripts at

http://www.hindawi.com
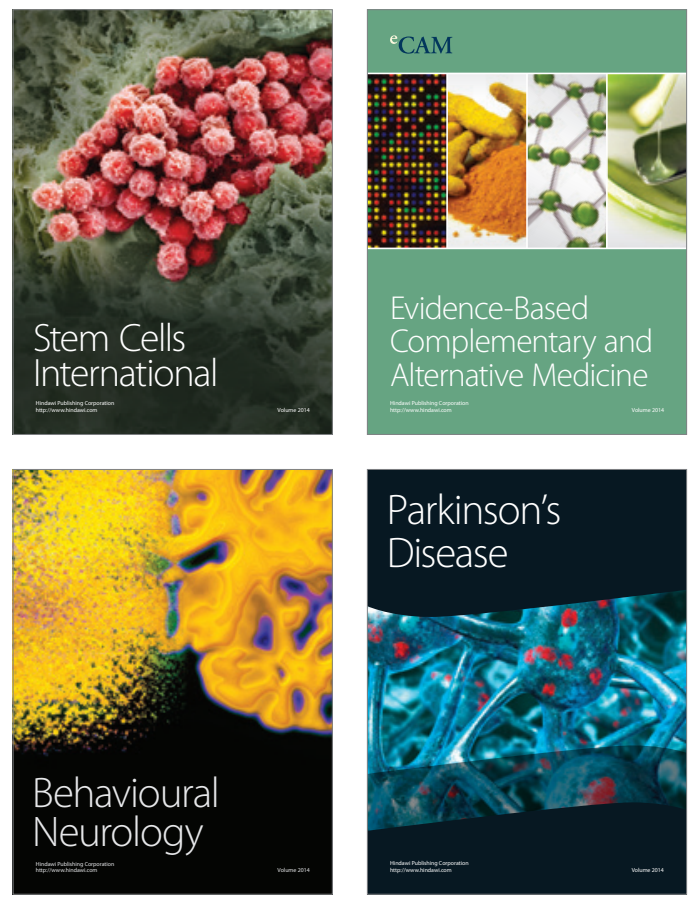
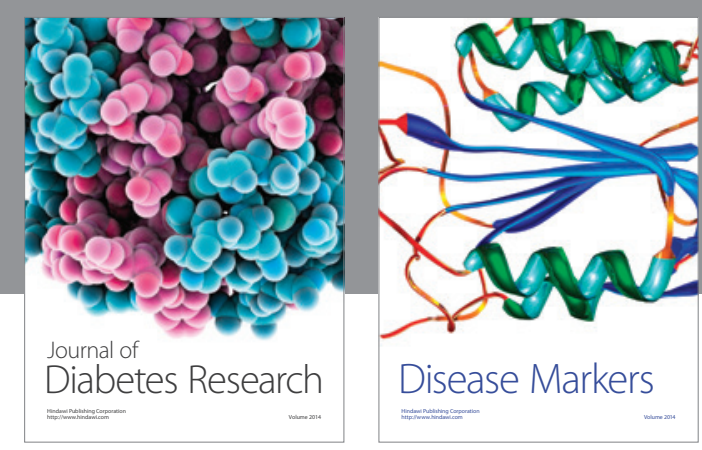

Disease Markers
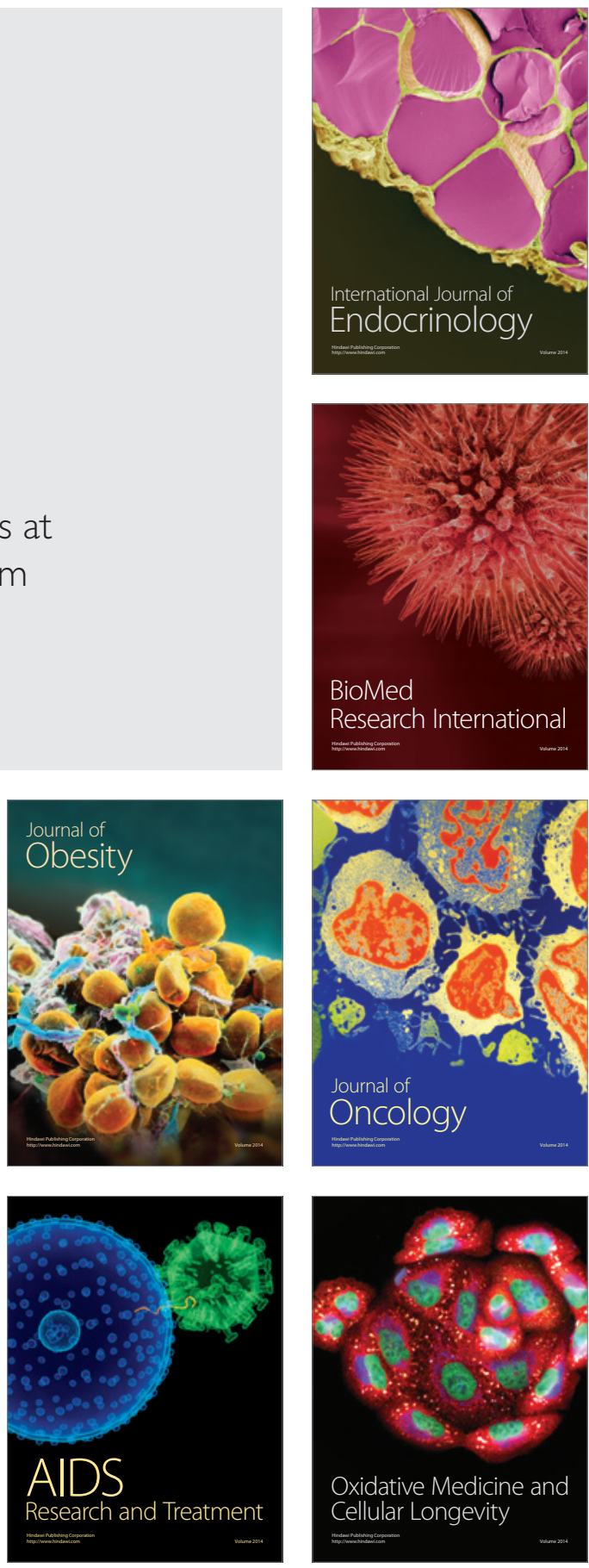